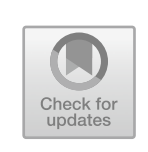

\title{
Complexity, Crises and Coping Strategies
}

\begin{abstract}
Wicked problems are shaped through complex system dynamics and involve multiple stakeholders. Public concern about wicked problems is often generated through crises that provoke awareness and intensify a wide sense of urgency. This chapter outlines some key aspects of crises that affect how wicked problems are perceived, debated and managed. Importantly, some 'creeping' crises develop gradually over an extended period with slow cumulative impacts, and there is uncertainty about when to accord them high priority. Other crises are immediate and fast-moving, giving rise to general acceptance of the need for rapid responses. In many cases, there will be serious disagreements about policy responses, owing to the complexity of causal factors and the diversity of stakeholder values and opinions. Some crisis-induced challenges can be well managed in the short term, leading to a return towards 'normal' life, but most responses do not explicitly tackle the complex underlying causes that generate the crises. Finally, it is suggested that the governance of wicked problems is less about designing elegant science-based solutions and more about implementing 'coping' strategies, which manage uncertainties, strengthen community capabilities and build resilience across all sectors-social, economic and environmental.
\end{abstract}

Keywords Complexity - Creeping crisis - Cumulative crisis - Acute crisis - Disaster management - Risk management - Prevention .

Resilience · Coping strategies · Uncertainty

(C) The Author(s) 2022

B. W. Head, Wicked Problems in Public Policy, https://doi.org/10.1007/978-3-030-94580-0_4 


\section{INTRODUCTION}

Wicked problems are framed and managed through highly political processes. Wicked problems are large, complex and entangled. They evolve over time. They display knowledge uncertainties in relation to causes and impacts. Diverse stakeholders cannot agree about the key dimensions of the problems and the best policy responses. Therefore, it is unlikely that conventional linear approaches to problem analysis and policy design will generate robust, effective and broadly supported strategies for improvement. Chapter 3 outlined some ways in which government leaders have used various methods of hierarchical control and consultative management to address wicked problems. In many cases they focus on attempting to reframe and normalise the problems. This chapter suggests that policymakers typically give higher priority to wicked problems when the challenges are perceived as crises rather than as routine or familiar issues. The political visibility of a wicked problem is reflected in how it registers in public discussion about priorities. All wicked problems are complex, but many complex and difficult issues do not achieve political traction. They remain off the policy agenda, perhaps because they are seen as too complex and messy to handle or because they lack strong and persuasive advocates to champion their importance.

This chapter firstly outlines some key dimensions of complexity that help us recognise the importance of understanding systems and relationships. These complexities affect how leaders and stakeholders interpret policy problems and how they perceive the 'governability' of the challenges presented. Secondly, the complexity aspects of crises are outlined, with attention to different types of crises, slow and fast. The cumulative impacts of slow changes can reach thresholds or tipping points that lead to instability and more rapid change, for which policy systems may be poorly prepared. Other crises are driven by catastrophic events such as natural disasters, technological disasters, or mass violence. Here, societies have recognised the benefits of emergency response planning and coordination. Thirdly, the chapter raises the question of what counts as success in addressing crises and complex problems. It is suggested that clear cases of 'solving' the problem are rare, and that most outcomes are mixed and uneven. Much effort is rightly directed at building capabilities to avoid further deterioration of conditions. This is about coping with crises, repairing harms, and building resilience to withstand future threats and pressures. 


\section{Complexity Analysis for Public Policy}

Many scholars see a close connection between the discussion of wicked problems and the analysis of complex systems (Byrne \& Callaghan, 2014; Geyer \& Cairney, 2015; Geyer \& Rihani, 2010; Ney, 2009; Tiesman et al., 2009). The policy literature on 'complex systems' is growing rapidly. The OECD has endorsed the value of exploring 'how systems approaches can be used in the public sector to solve complex or "wicked" problems' (OECD 2017, p. 4). Its recent report on systems thinking states that seeking to change the 'dynamics of a well-established and complex system requires not only a new way of examining problems, but also bold decision-making that fundamentally challenges public sector institutions' (OECD 2017, p. 3).

Democratic governance is inherently challenging, marked by political competition between actors with divergent perspectives and priorities. Democratic governance is full of trade-offs and paradoxes (e.g. reconciling stability and change, effectiveness and legitimacy, efficiency and fairness, state and non-state responsibilities for action). Given these complexities and uncertainties, broad capacities for strategic policy design, inter-group negotiation and collaborative implementation are crucial. The simplifications of 'managerialist' decision-making and target-driven efficiency regimes are viewed with suspicion by complexity thinkers (Ansell \& Geyer, 2017; Eppel \& Rhodes, 2018; Room, 2011; Seddon, 2008). Colander and Kupers (2014) draw a sharp contrast between two conceptions of governmental policymaking and knowledge. The rational approach focuses on policy instruments that predict and control outcomes, whereas the complexity approach highlights multiple interactions and perspectives:

The policy metaphor in the complexity frame changes from an image of government behind the steering wheel driving on a well-lit road, to an image of government trying to drive a car, with the windshield covered in mud, going down an unlit, winding road, with hundreds of people grabbing the wheel. (Colander \& Kupers, 2014, p. 26)

Complexity theory, originally developed in the bio-physical sciences, draws attention to the multiple interconnections, feedback loops and surprising side-effects that can often undermine the aspirations of leaders to 'control' their socio-political systems. The term 'complex' is intended 
to signal the organic and interactive aspects of systems, rather than the mechanical aggregation of elements or components. For example, Foden (2018) playfully emphasises the difference between (1) understanding and influencing the behaviour of a sophisticated living organism, such as a cat, and (2) understanding and influencing the operating mechanism of a simple machine, such as a clock. Peter Senge (2006, Chapter 6 and Appendix 2) talks about the difficulties of understanding and responding to systems, and the typical errors and failings that arise from these misapprehensions.

A core tenet is that a 'system' understanding is needed to understand how the structure of the system influences the behaviour of the system. This is different from the standard approach of focusing on events/issues (e.g. an algal bloom) or a trend (e.g. increasing nutrient levels in a river basin), which are a typical focus of policy action but may not tackle the underlying structural issues. Complexity analysts in public management and public policy have argued that the modern era is marked by crises and rapid changes that 'cascade' across borders and across policy domains. These problems are so serious that they 'challenge the steering capacity of governance' (Duit \& Galaz, 2008, p. 311). Accordingly, analysts need to research 'the problem-solving capacity of existing multilevel governance systems in the face of change characterized by nonlinear dynamics, threshold effects, and limited predictability' (Duit \& Galaz, 2008, p. 329).

In policy analysis for health systems, Glouberman and Zimmerman (2002) distinguish between the 'complicated' technical and managerial knowledge required for managing modern health service systems (based on applying professional expertise to address known challenges) and the more 'complex' and contestable aspects of designing healthcare systems. The 'complexity' dimension in this example denotes the disagreements on values, ideologies, priorities and partner responsibilities. Such disagreements in healthcare can occasionally lead to policy gridlock and polarisation concerning the design of service systems and the balance of public/private roles. The literature on public health policy and services has further elaborated on the theme of 'complex systems' analysis (e.g., Carey et al., 2015; Hawe, 2015; Peters, 2014) in order to make sense of the interactions between various levels of activity, multiple actors and conflicting goals in healthcare. A systems approach can make use of both qualitative and quantitative information to construct models of how various factors and proposed actions may interact to produce not only 
desired effects but also unintended effects (Hawe, 2015; Haynes et al., 2020; Lich et al., 2013).

The field of environmental policy research (further detailed in Chapter 5) has also embraced complex systems analysis, including extensive work on the management of natural resources, ecological systems and climate change responses. Systems thinking emphasises the need for interaction and discussion among experts and stakeholders to map the dimensions of risk and disruption, and to consider a range of pathways to address these risks (Ison \& Straw, 2020). The tendency for decision-makers to demand knowledge certainty might privilege calculative methods such as cost/benefit analysis rather than broader combinations of knowledge and experience that can better deal with the complex risks and uncertainties of emerging issues (Stirling, 2010).

The literature on complexity in public administration has also demonstrated that good coordination and planning are crucial (Christensen et al., 2016; Kettl, 2003; Pierre \& Peters, 2005) for ensuring that responsibilities and priorities are clarified, implementation activities are well-resourced, monitored and adjusted (Kiel, 1994), and that governance networks and stakeholder participation are well managed (Koliba et al., 2011). This approach is broadly consistent with the ecological literature on 'adaptive governance' (Chaffin et al., 2014), which highlights the importance of capacities to respond to the inevitable shifts occurring within complex systems. Traditional process-oriented management of projects and programs is regarded as too inflexible and bureaucratic to address the unpredicted and unintended outcomes of system changes and to engage with ripple effects and spill-overs. Adaptive leadership is needed to renegotiate the trade-offs among policy objectives and stakeholder interests, while preserving the governance legitimacy built through shared goals. Similar themes have emerged in research on the multiple entangled issues inherent in the policy and planning regimes of large cities. The findings in the classical studies by Pressman and Wildavsky (1973) and by Rittel and Webber (1973) have been elaborated in many recent studies. For example, Karen Christensen found that complexities abound in the interactions between layers of city government and industry sectors, and across several types of issues. She also detected several forms of innovation and learning in city planning (Christensen, 1999, p. 96).

What are the knowledge challenges of coping with complexity? Some forms of complex problems (such as designing and building infrastructure) can be addressed through high levels of coordination, managerial 
efficiency, technical skills and sufficient funding, whereas other forms of complexity are characterised by high levels of knowledge uncertainty and disagreement about objectives. Reliable knowledge about future trends and social disruptions is seldom available, especially when some of the causal factors underlying a major crisis are outside the control of national decision-makers. Gaps in knowledge are normal; and attempts to fill these gaps are constantly being undertaken by both scientists and practitioners. However, the organisational context is also very important. Emery Roe's analysis of the reliability challenges facing the managers of infrastructure enterprises (water, energy, transport) found that there were three forms of unpredictability: (1) low risk with key factors known and controllable; (2) some uncertainties where the likelihood or impact of reliability failure are not known; and (3) high uncertainty (many unknowns) regarding both likelihood and impacts. Roe argues that these situations correspond with three operating styles-controlling, adaptively managing, and coping with instabilities (Roe, 2020 p. 76). Roe argues that more attention should be given to situations where 'control' is not possible and where uncertainties have to be the focus of networked discussion.

Management consultants in the 1990s developed a classification of knowledge adequacy. Knowledge that is regarded as robust and relatively complete is described as the field of 'known knowns'. More relevant to wicked problems, knowledge gaps that have been identified in key areas of concern constitute the field of 'known unknowns'; these become a major focus for scientific research and practitioner learning. Beyond the comfort zone of existing reliable knowledge and calculation lies the sphere of 'unknown unknowns', understood as a realm of radical uncertainty, and a massive challenge for scientists, practitioners and decision-makers. Donald Rumsfeld, when US Secretary of State, focused on identifying 'unknowns' relevant to potential hostile threats to US security. Rumsfeld noted that it was very difficult to anticipate such threats, and to plan for appropriate and timely responses, in the absence of clear and abundant evidence (Rumsfeld, 2011, p. xiv). In foreign policy decision-making by the White House, especially after the 9/11 terrorist strike against the World Trade Center in New York, this preoccupation with the challenges of 'unknown' security threats became transformed into the doctrine of 'pre-emptive' action, whose primary goal was to ensure that hostile states and terrorist networks did not access weapons of mass destruction (Dershowitz, 2006, Ch 5; Suskind, 2006, pp. 62, 150). Pre-emptive action against terrorism 
has been described as especially risky and contentious (Stern \& Wiener, 2006).

However, the urgent and well-funded responses to military security challenges can be contrasted with the weaker governmental responses to several other high-impact policy challenges. For example, in the field of US climate change policy, with its powerful corporate stakeholders and slow timelines, there has been a notable absence of precautionary and pre-emptive actions backed by well-funded programs. A high sense of urgency has not been strongly conveyed to the political executive in many countries by core stakeholders through public debate and community pressures. Debates about problem framing are highly relevant for complex issues. For example, 'climate change' can be framed as a scientific issue with expert technical solutions, or as an economic livelihoods issue where the policy response could focus on creating new jobs. Heather Cann (2021) shows that a climate and energy policy reform package was endorsed by the Illinois legislature owing to its economic orientation.

The character of each wicked problem may be very hard to discern, owing to complexity, uncertainty and divergent perspectives. Renn and colleagues have argued that 'risk governance' at a system level is fundamentally shaped by the need to deal with complexity, uncertainty and ambiguity (Renn et al., 2011). Conventional research projects, whether basic or applied, are generally targeted at filling known gaps in knowledge. Knowledge is generally patchy, and research aims to accumulate more information in order to tackle the 'known unknowns' (Pawson et al., 2011). However, the disruptions and surprises associated with new crises can raise concerns about the radical uncertainties of 'unknown unknowns'. What kind of knowledge and expertise are needed in situations where-as Funtowicz and Ravetz $(1993,2003)$ remind us-facts are uncertain, values are disputed, stakes are high, and decisions are urgent? In this 'post-normal' challenge to the knowledge base for policy action, conventional scientific methods of data collection and analysis are seen as too narrow and too slow to grasp the complexities of rapid change. Network-based forums of diverse experts and stakeholders are recommended to examine the implications of possible future scenarios under conditions of uncertainty (Gerlak et al., 2021). Strategies for coping with uncertainty and turbulence 'should not be about predicting the futurewhich is unpredictable by definition - but about devising methods and systems for handling the unexpected' (Grint, 1997, p. 64). Aven and 
Renn (2010) have argued that different processes are needed for eliciting relevant knowledge for risk analysis and policy response, depending on the nature of the knowledge challenge-for example, is it a problem of causal complexity, uncertainty about impacts, ambiguity arising from value differences, or all of these together? (Aven \& Renn, 2010, p. 187).

Policy analysts have outlined the processes by which problems are debated and 'managed' until they reach a provisional conclusion. Relatively simple or 'tame' issues with agreed solutions tend to settle into routine patterns of administration, in which incremental adjustment and performance monitoring are accepted as the dominant modes of governance. But sometimes the underlying issues may not be permanently resolved through policies decided and programs implemented. Contests about problem framing and prioritisation are recurrent. Given the complexities arising from various forms of stakeholder conflict and knowledge uncertainty, the policy governance challenge is to identify processes for dealing with the messy, ambiguous, controversial or unstructured nature of wicked problems. This policy governance challenge is exacerbated by the fact that the political theatre of public debate tends to focus on the more controversial and emergent policy problems-those which tend to require 'non-routine' processes to help identify long-term policy responses that are effective, feasible and legitimate. Serious gaps in knowledge and understanding may increase the likelihood that policy decisions about crises and wicked problems will be based primarily on leaders' intuitions or political ideologies. This is especially risky for policy crises on high-stakes issues. The different types of crisis situations and different policy responses are discussed in the following section of this chapter.

\section{Types of Crises Shaping Wicked Problems}

Crises are never welcome, but they can provide opportunities to reflect on our taken-for-granted assumptions about goals, methods and processes. In the COVID-19 pandemic crisis of 2020-2021 the initial focus on containing and mitigating the rate of infection has been joined by discussions about 'building back better'. In other words, the crisis might create space for wider discussions about social values and equity as well as about boosting economic investment and employment. In short, crises can generate either knee-jerk political responses or can facilitate deeper reflection on strategic direction and the need for new thinking. As Hannah Arendt noted: 
A crisis forces us back to the questions themselves and requires from us either new or old answers, but in any case direct judgments. A crisis becomes a disaster only when we respond to it with pre-formed judgments, that is, with prejudices. Such an attitude not only sharpens the crisis but makes us forfeit the experience of reality and the opportunity for reflection it provides. (Arendt, 1977, p. 171)

The political framing of complex problems emerging in response to various types of crisis provides the canvass on which the terms of policy debate are displayed. Conflicting narratives emerge in relation to the nature of the events that trigger the sense of urgency (Birkland, 1998). Governments must respond to the different perceived challenges posed by a crisis, and they seek to influence the associated 'framing contests' (Boin et al., 2009). Debates rapidly emerge about who should be blamed for the crisis, who should be responsible for 'fixing' the problem and what would count as success in the estimation of various stakeholders. Crises take many different forms and may arise in many different situations (Drennan et al., 2015). They are frequently assessed by crisis analysts in terms of the likelihood of their emergence, the severity of their impacts, their duration, their propensity for preparedness or contingency plans, and their degree of politicisation.

Two broad categories of crisis may be distinguished, focused on either acute events or slow-onset and 'creeping' risks. Firstly, some crises are caused or triggered by sudden events with massive impacts-biophysical, technological, economic, political or environmental. Diverse examples might include nuclear-technology disasters at Chernobyl (1986) and Fukushima (2011), natural disasters (hurricanes, tsunamis, floods, volcanic eruptions, earthquakes), massive oil spills, critical infrastructure damage, fiscal collapse, mass violence or political regime disintegration. These are very different situations, with a mix of random, accidental and malicious causation. Some such crisis events are amenable to anticipatory planning and emergency response interventions. Specialised teams can be mobilised in accordance with established plans for recovering from natural disasters, and technical teams can be deployed to restore critical system functions. The restoration of political governability, and the rebuilding of robust financial systems are much more complicated. Relative success might be measured in terms of scope and speed of interventions. But 'learning' from crises (in order to reduce the incidence of future harm) 
is a much larger challenge. In all these cases, organisational capacities are crucial for effective outcomes.

Secondly, some crises are generated through the slow development of patterns or activities ('creeping crisis': Jarman \& Kouzmin, 1994) that may eventually reach a critical threshold. There may be serious delays in recognising that these risks have developed to a point where they will require urgent attention. When awareness increases, the latent or creeping crisis becomes more visible to stakeholders who become more motivated to demand responsive action (van Buuren et al., 2016). These 'tipping points' (indicated by evidence of serious harm) generate narratives to strengthen the shift from problem-recognition to high priority action. The cumulative impacts of a slow-onset crisis-for example in environmental and natural resource management-have built up over a long time period. Examples might include drought-induced desertification, environmental pollution (water, air and soil quality), and the deterioration of ecological assets (such as loss of biodiversity, the destruction of old-growth forests, and depletion of ground-water resources through the large-scale expansion of agriculture). The UN Framework Convention on Climate Change identified eight types of slow-onset phenomena linked to climate change: increasing temperatures, sea level rise, salinisation, ocean acidification, glacial retreat, land degradation, desertification and loss of biodiversity.

The global community seems to be confronted regularly with massive disasters where lives are lost through famine and disease. Global scale problems include climate change and the pressures of population growth. Such examples are featured in the 17 Sustainable Development Goals championed by the United Nations (see https://sustainabledevelopment. un.org/sdgs). These complex and intractable challenges are widespread across many geo-political areas but they have differential impacts across various scales or levels (local, regional, national, global).

From a public policy perspective, there are serious concerns about whether government leaders recognise and understand the full significance of crisis situations, except in a self-interested way to ensure their political survival. Some of these crisis situations can be anticipated and mitigated, so that emerging threats could be well managed if not prevented. For example, crisis events that are periodic or cyclical, such as natural disasters, can be anticipated, hence they gradually become the focus of contingency planning and emergency response services. These 
anticipatory actions are formalised as funded programs led by professional specialists in emergency management.

However, there are two very different types of crisis in which anticipatory planning is likely to be either overlooked or very weak-creeping crises with slow and cumulative impacts, and fast-changing turbulent crises. In the first type, the slow onset of a crisis may obscure the underlying processes of intensification of risks and threats; in this case, the policy agenda may fail to accommodate the necessary preventive or preparatory work. Examples include climate change policy responses, and governmental indifference to the steady decline in the indicators of biodiversity health and other ecological assets. Delays in taking action can lead to compounding or cumulative harms, with spillover effects in related problem areas. Protracted conflicts can have tragic consequences:

The consequences of protracted conflicts are often dire, including high economic costs, destruction of vital infrastructure, division of families and communities, extreme violence, dislocation, trauma, and intergenerational perpetuation. (Coleman, 2003, p. 5)

With some forms of crisis, challenges are not only complex but are also turbulent. This means that the development of the problem is 'surprising, inconsistent, unpredictable, and uncertain' with no 'ready-made solutions' (Ansell et al., 2021, p. 2). In a turbulent situation, the advocates of collaborative approaches suggest that leaders must seek 'robust' governance solutions that are sufficiently 'adaptable, agile and pragmatic' to pursue goals or functions despite continuous disruptions. Leaders must 'abandon the idea of restoring a past equilibrium', instead engaging in an adaptive search for 'institutions, regulatory processes, and policy instruments to meet new and emerging conditions' (Ansell et al., 2021, p. 4). Other analysts agree that adaptive leadership, institutional capacities and flexible policy designs are crucial (Capano \& Woo, 2018; Howlett et al., 2018; Nair \& Howlett, 2016). This perspective accords with much of the literature on managing risk and uncertainty. Roe claims that in areas of high uncertainty, leadership is less about designing solutions than about managing networks of professionals and knowledge-holders (Roe, 2013, p. 98). Brugnach and Ingram argue that standard knowledge systems cannot cope with high uncertainty and high disagreement; and they call 
for 'knowledge co-production processes' that can achieve effective 'integration based on deliberation, open space for dialogue, negotiation and learning' (Brugnach \& Ingram, 2012, p. 60).

In considering the interaction between complexity, crises and wicked problems, it is important to appreciate the linkages between different fields of policy and practice, and the cascading effects from one area spilling into adjacent areas. The think tank Future Earth commissioned a survey of global risk perceptions among 200 scientists from diverse countries. A key finding was the strong interconnections seen among five global risks: climate change, extreme weather, biodiversity loss, food crises and water crises. These risks had the greatest 'potential for synergistic effects that could lead to a global systemic crisis' (Future Earth 2020, p. i) (see Fig. 4.1 for the perceived interconnections).

\section{Strategic Risk Management-The EXAMPLE OF COVID-I9}

In recent decades there has been increasing awareness of the large scale and urgency of problems facing public leaders, policy advisors and institutions. The repeated outbreak of contagious diseases that proved difficult to control (HIV/AIDS, SARS, Ebola, COVID-19 and others) undermined confidence that modern science has overcome the major threats to population health. At the same time, the fear of terrorist violence and the governmental response ('war on terror') reinforced widespread concerns about increased risks to human well-being on many fronts. In short, there have been interacting series of cascading crises which have posed massive challenges for policy governance. In response, a growth industry in risk management advice, forecasting and scenario analysis has emerged (Power, 2007). Given the large scale and wide scope of these disruptive factors, international organisations have also become prominent in analysing the main threats to stability and security.

Thus in 2011 the Organisation for Economic Cooperation and Development published an influential study of 'future global shocks' which emphasised the significance of four themes: pandemics, financial crises, cyber risks and the destructive impact of massive storms (OECD 2011). The World Economic Forum in 2017 released its 'global risks' report which identified the following as the five 'most likely' major risks: extreme weather events; large-scale involuntary migration; major natural disasters; large-scale terrorist attacks; and massive incidents of data 


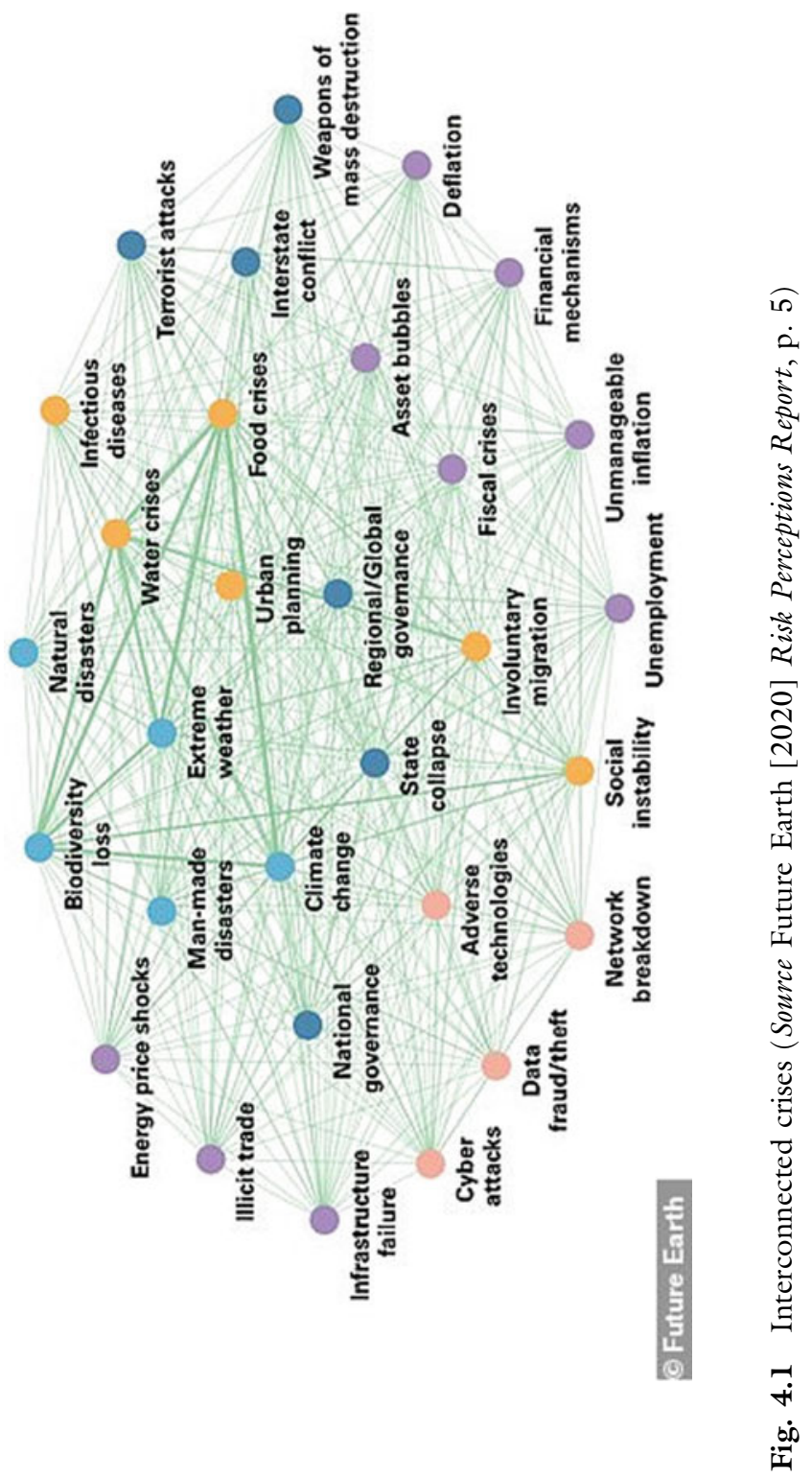


fraud/threat. However the list of top five global risks in terms of severity of 'impact' were different: systemic financial failure; water supply crisis; food shortage; chronic fiscal imbalances; and extreme volatility in energy and agricultural prices (WEF, 2017). Two years later, before the COVID19 pandemic, the World Economic Forum claimed that the six 'most likely' major risks were: extreme weather events; failure of climate change mitigation and adaptation; natural disasters; data fraud or theft; cyberattacks; and man-made environmental disasters. In the same report, the WEF identified the following as the top six risks in terms of severity of 'impact': weapons of mass destruction; failure of climate change mitigation and adaptation; extreme weather events; water crises; natural disasters; and biodiversity loss and ecosystem collapse (WEF, 2019).

With hindsight, it is interesting to see how the perceived threats shift over time. Everything changed in 2020-2021 with the arrival of COVID19, which had catastrophic effects on jobs, incomes, revenues and the movement of people and goods. The World Economic Forum's report in 2021 listed pandemics as the fourth 'most likely' global risk and the top item in terms of 'impact' (WEF, 2021). Public health analysts were sensitive to the challenges and interconnected risks:

By all three measures of wickedness - complexity, uncertainty, and divergence - COVID-19 is a highly wicked problem, and will continue to be at least until there is an effective and universally available vaccine. (Núñez-Corrales \& Jakobsson, 2020, p. 3)

In early 2020 the World Economic Forum commissioned a special study about the economic, social and governance implications of the new pandemic. According to this report, health system capacities are typically undermined by political considerations and competing priorities:

Pandemics have traditionally suffered from a panic-neglect cycle. Quiet periods see no action, early warnings of an outbreak tend to be overlooked, significant response and funding are late and uncoordinated, and valuable lessons from the crisis are not institutionalized. (WEF, 2020, p. 11)

Pandemic crises have massive effects that are unevenly distributed across countries and across social classes. Experts have been attempting to develop more targeted public health responses taking account of large differences in the demography of various locations: 
COVID-19 poses a dramatic challenge to health, community life, and the economy of communities ... [but] the impact has been dramatically different from place to place, due to such factors as population density, mobility, age distribution, etc. Thus, optimum testing and social distancing strategies may also be different from place to place. (Núñez-Corrales \& Jakobsson, 2020, p. 1)

In 2020, COVID-19 shut down economic activity, overloaded health services, infected over $70 \mathrm{M}$ people and caused $1.7 \mathrm{M}$ deaths; and in 2021 both the incidence of infections and the number of deaths was even higher, despite the commencement of new vaccination programs. The capacity of national governments to respond effectively was seen to be highly variable across the globe (Capano et al., 2020). Some leaders deliberately downplayed the issue and ignored medical advice, with dramatic consequences for infection rates and mortality. The rationalist assumption that reliable scientific knowledge of causes and remedies would be readily available, and that effective measures could be quickly deployed, was sorely tested at every level. Some experts urged the importance of recognising gaps and uncertainties in knowledge, and the need to take an adaptive and precautionary approach (Berger et al., 2021).

The crisis posed vigorous challenges for the ability of governments to pursue collective goals in an adaptive and inclusive manner under conditions of turbulence (Ansell et al., 2021). The challenges were not simply administrative, as in logistics and coordination, but also raised important ethical dimensions in choosing between policy strategies to protect vulnerable populations through lockdowns and strategies to maximise business-as-usual. Arguments immediately emerged about which values and goals should be prioritised. These goals included:

... reduction of COVID-19 morbidity and mortality, the mitigation of long-term social repercussions of containment policies (rising social inequalities, mental health issues due to social isolation, intergenerational conflicts) and financial adverse consequences, in the form of severe economic recessions, and subsequent rise in unemployment, poverty levels, and social tensions. (Angeli et al., 2021, p. 2)

Pandemics also generate competing narratives about causes, location of first outbreaks and reasons for rapid spread. The surface layer of explanation, often politicised, focuses on where the first outbreak was 
recorded, the competence of local authorities in implementing containment measures and the prospect of effective vaccines guaranteeing public health and security. A much deeper 'systems' layer of explanation (Dobson et al., 2020; UNEP, 2021, p. 22) is that viruses of this type have originated in wildlife; they have been transmitted into human populations through unguarded close contacts ('zoonotic' transmission); and this pattern will recur if economic development policies continue to facilitate the expansion of food production areas at the expense of undisturbed forest areas. Crises can also reveal vulnerabilities in systems that we have assumed are reliable. A simple example is the food supply chain. The COVID-19 pandemic has shown that the food production, distribution and retail sectors can be badly affected when the free mobility of goods and services is heavily constrained and when economic recession becomes global. The usual cyclical causes of food insecurity - such as droughts and floods-are intensified when a wider crisis such as a pandemic disrupts economic markets. In responding to the pandemic crisis, governments have also upgraded their data systems for surveillance of citizens and restricting their movement; but civil rights activists have been concerned to ensure these measures are proportionate to the problem and would be utilised in transparent ways only for the duration of the emergency.

\section{Prevention, Coping and Adaptive Strategies}

Policy debates about how to manage wicked problems are often focused on making decisions about a specific action-such as modifying a regulatory framework or funding a new service or facility. These short-term interventions are often seen as popular and useful. They might 'make a difference' in two ways-political leaders could strengthen their electoral stature by taking visible action; and a well-targeted policy could distribute tangible benefits to stakeholders and achieve measurable improvements. But a short-term policy agenda of 'business-as-usual' with incremental adjustments will usually neglect the underlying causes of larger problems, as noted in Chapter 3. In other words, the downside of incrementalism is that attempts to tackle the serious intractable issues are not only delayed, but are also likely to become much more costly and difficult for later generations to tackle (Nair \& Howlett, 2016, 2017). If government leaders are preoccupied with short-term gains, and if they have limited political incentives to invest in developing long-term policy strategies, some of the required new thinking will have to come from 
outside government-through community and business groups, think tanks, research institutes, innovation networks and new media platforms.

Policy practitioners and policy analysts in democratic countries have increasingly been obliged to tackle wicked problems, but with limited success. Their dilemma is threefold: how to (1) design and implement effective policies, (2) through processes that maintain civic legitimacy (3) under conditions of flux and uncertainty. If wicked problems are characterised by complexity, divergence and uncertainty, then the relevant policy decisions and programs can only represent temporary settlements rather than definitive solutions.

In many cases the magnitude of the problem is daunting, and what counts as 'success' is necessarily modest. In situations of serious conflict between hostile stakeholder groups, with latent or actual violence, negotiating an accommodation between opposing groups might itself be a significant achievement, and might provide a basis for future improvements. The extensive literature on conflict-reduction strategies-extending from international peace-keeping processes (Wallensteen, 2019; Williams \& Bellamy, 2021) through to resolving environmental disputes (Lewicki et al., 2003; O'Leary \& Bingham, 2003)—provides an important corrective to those technocratic science-driven approaches that are dedicated to producing optimal solutions.

If optimal data-driven solutions are elusive, as is likely for wicked problems, what are the alternatives? Stakeholder-oriented approaches propose that seeking accommodation among stakeholders is the best approach, through inclusive processes of dialogue that consider shared goals and best-available evidence. The inherent difficulties of each problem are highly variable, and the nature of feasible improvements will also vary. In some policy areas there can be positive gains and a narrowing of disagreement about goals and methods. But in other policy areas, the conflicting perspectives may be so entrenched that agreement is not possible, or the scale and complexity of the problem may be so massive that future improvements are seen as distant aspirations. If intractable problems cannot be 'fixed' in a clear and definitive way, but they can be more-or-less 'well managed', then the language used for framing policy goals should reflect this shift in understanding. And if the planning context is turbulent, unpredictable and disrupted by crises, policy aspirations should recognise the value of stabilisation and resilience rather looking for neat definitive solutions or repeating the traditional panaceas of continuous growth and prosperity. 
While the policy challenge varies greatly across social, economic and environmental policy fields, the above understandings of how to manage crises and wicked problems utilise key terms such as prevention, coping, resilience and recovery; and the corresponding policy development style emphasises adaptive management, learning and inclusive discussion. The concept of resilience-much discussed in ecology and environmental policy-is outlined in Chapter 5. The concept of prevention has been used in a wide array of social policy strategies, as further discussed in Chapter 6, and was prominent in the social programs of the UK Labour government of Blair and Brown 1997-2010. Prevention has also been a central theme in international relations and diplomatic processes aimed at peace-building. For example, the reports of the UN Secretary-General concerning the prevention of armed conflict and prevention of other global crises have emphasised the importance of preventive policies for averting traumatic conflicts and for advancing the conditions necessary for achieving the diverse Sustainable Development Goals (United Nations, 2020).

This approach argues that long-term preventive strategies (e.g. welfare services) can form a kind of policy safety net that can support a host of more specific initiatives for policy improvement, examples of which are discussed in later chapters. Prevention policies represent an alternative to the political stance of leaders who claim to be 'solving' major problems. Rather than solving tough and intractable problems, the more realistic focus of modern governance is often about 'coping' and recovery (Head, 2022). Where there is a regular cycle of recurrent crises, such as natural disasters, the focus on improved 'coping' leads to the strengthening of crisis preparedness-through new investments in response capacities, involving stakeholders in planning processes, and creating opportunities for learning. In most rich countries, emergency services have become well-resourced and professionalised as part of contingency planning.

In addressing the ongoing challenges of poverty and the social determinants of poor health (Taylor et al., 2016), the main focus in recent decades has been preventive programs that investigate and mitigate the underlying systemic causes of social disadvantage. Building on the shared knowledge of researchers, practitioners and clients of service programs, prevention programs aim to tackle the 'upstream' factors that cause the 'downstream' harmful effects. Prevention is a long-term approach for better managing known risks which have been shown to 
underlie embedded problems and systems. The dual purpose of preventive programs is firstly to identify and reduce avoidable risk factors that cause social harms, and secondly to design positive pathways for improving the skills and well-being of vulnerable groups. There are many examples of this approach in public health (Hochlaf \& Quilter-Pinner, 2020), crime reduction (France \& Homel, 2007), countering violent extremism (Weine et al., 2017), tackling poverty and persistent inequalities (Van Ryzin et al., 2018), education and training programs, and services to reduce family violence and child abuse. Prevention efforts in social programs and public health distinguish between three focus levels. 'Primary' prevention services are generic and aimed at the well-being of the whole population, e.g. universal services in school education and primary healthcare. 'Secondary' prevention programs target social groups at higher risk of harm, through early intervention services to improve their pathways towards well-being. These targeted programs are typically based on detailed social evaluation studies to guide the cost-effective use of scarce funding (Freeman, 1999). 'Tertiary' prevention programs treat chronic conditions and overlap with mainstream service programs.

Evaluation research on the costs/benefits of various approaches has consistently demonstrated the benefits of shifting more public investment into preventive programs. By comparison, crisis and emergency services are inherently very expensive. The economics and social science of prevention have provided persuasive evidence to policymakers, but governments have found it difficult to take larger steps towards adopting the new paradigm. Why are preventative programs less popular with politicians than building new infrastructure? In the field of natural disaster management, for example, an Australian report identified that governments tend to 'overinvest in post-disaster reconstruction and underinvest in mitigation that would limit the impact of natural disasters in the first place' (Productivity Commission, 2014, p. 2). There have been widespread debates about how to shift the balance between spending on crisis response services (e.g. hospital emergencies) and spending on risk reduction and mitigation (e.g. health education).

There are several challenges for policy-makers and service professionals wanting to shift the investment balance from emergency services towards preventive programs (Boswell et al., 2019; Cairney \& St Denny, 2020; Head \& Redmond, 2011; Kennedy, 2020). Faced with a choice between funding hospitals and funding community health services, governments may prefer to take the credit for tangible artefacts such as buildings 
and medical technologies. Policymakers may find it difficult to shift resources into long-term prevention while media-enhanced demands for crisis services remain high. Decision-makers are under pressure to respond quickly to real and perceived crises. Media attention focuses on critical incidents, and urges redress for abused, injured or harmed individuals. Commissions of inquiry (Stanley \& Manthorpe, 2004) often recommend improvements in rapid response systems and crisis monitoring rather than prioritising the long-term benefits of programs to assist disadvantaged families and children. There are also political and fiscal constraints on shifting priorities towards prevention. Prevention requires financial commitments to be locked-in for many years, but the demonstrable benefits are deferred. The delayed nature of the benefits can make long-term investments less attractive for politicians who are navigating short-term electoral cycles. Prevention programs face competition in the budget process from many electorally-appealing alternative proposals. The advocates of prevention policy also have to contend with the psychological disposition to 'discount' possible future benefits against the current array of entrenched benefits (Kahneman, 2011). Finally, the need to maintain long-term commitment is threatened by continual changes in government ministers and key program managers.

\section{Conclusions: Coping with Complexity}

Political considerations largely determine which policy approach, or combination of approaches, will be implemented. Some strands of conservative thought have been comfortable about 'coping' as a political skill that seeks incremental adjustment and avoids over-reaction (Moynihan, 1973). In political practice, there are many examples of coping and adaptation strategies by both reformers and conservatives, and these strategies may co-exist alongside projects to promote rapid policy innovation in response to challenges. Coping strategies are likely to be found where several major problems intersect, or where problem-solving resources and capacities are low, or where layers of organisational and program change are piled together simultaneously. The wicked problems literature is gradually recognising that 'coping' (Daviter, 2017; Head, 2010c, 2022) and iterative adaptations to address changing conditions may be useful both for maintaining past achievements and for planning future benefits.

Coping can be a valuable and even necessary approach under conditions of adversity and complexity. For example, coping has been identified 
by food security researchers as a survival mechanism by which poor and vulnerable populations respond to food shortages. When threats to food security are recurrent and predictable, more adaptive responses to adversity may emerge (Davies, 2009). More broadly, coping behaviours and strategies can take several forms in different locations, from individual workplace behaviours through to institutional processes of change. Much of the previous literature on 'coping' in the public sector has focused on how individual staff deal with the stresses of their work under conditions of overload, rapid change and austerity (Tummers et al., 2015). Public servants are continually obliged to reconcile value conflicts and ambiguous objectives as part of their adaptive professional work (de Graaf et al., 2016). Public policy research also needs to consider the institutional challenges of policy design, where approaches to managing value conflicts can be tackled at a strategic level.

According to Daviter, 'coping strategies aim to reflect the fragmented, uncertain and ambiguous nature of wicked problems by relying on a more disjointed and tentative process of formulating policy responses' (Daviter, 2017 , p. 578). On the one hand, this suggests that there are many elements and dimensions of wicked problems that need to be mapped, debated and tackled (Alford \& Head, 2017). On the other hand, the rational quest for comprehensively integrated and joined-up approaches for managing wicked problems might not always be feasible and could be unnecessary, in cases where an iterative and decentred approachwith multiple local initiatives and 'small wins'-would suffice to achieve progress (Termeer \& Dewulf, 2019; Termeer et al., 2015; 2019; Weick, 1984). This perspective on small wins is highly relevant for debates about the desirable speed and the multiple levels of reform required to address large and urgent problems. There will always be political differences between those who demand transformation and those who adopt a goal-directed pragmatism that supports incremental shifts on many fronts towards a new paradigm. These debates are highly relevant to the environmental and social problems discussed in the following chapters. 
Open Access This chapter is licensed under the terms of the Creative Commons Attribution 4.0 International License (http://creativecommons.org/licenses/ by $/ 4.0 /$ ), which permits use, sharing, adaptation, distribution and reproduction in any medium or format, as long as you give appropriate credit to the original author(s) and the source, provide a link to the Creative Commons license and indicate if changes were made.

The images or other third party material in this chapter are included in the chapter's Creative Commons license, unless indicated otherwise in a credit line to the material. If material is not included in the chapter's Creative Commons license and your intended use is not permitted by statutory regulation or exceeds the permitted use, you will need to obtain permission directly from the copyright holder.

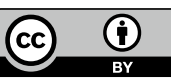

